provision in terms of medical and nursing staff and hospital beds. Even paediatric waiting lists are positively associated with the number of local authority med ical staff (table C), discharge rates (both perinatal and among children aged 0-4, table A), and only one index of need (the percentage of the population under 15 years). These indices of use, highly associated with provision, should not be confused with indices of need. So long as the demand for medical care is measured in terms of met demand-for example, in terms of the paediatric inpatient attendance rates or the number of antenatal attendances per birth-and not in terms of need, regions with high provision will be able to justify their high medical establishments and numbers of beds and even present a case for more resources by describing their use statistics as indicators of demand and, therefore, as indicators of need. A clear distinction should be made between those indices of use (or met demand) that are highly dependent on service provision and the real needs of the population for a health care service.

The unpublished tables and appendices may be obtained from Professor Lowe, Department of Social and Occupational Medicine, Welsh National School of Medicine, Heath Park, Cardiff CF4 4XN.

\section{References}

${ }^{1}$ Registrar General's Statistical Review of England and Wales, Part I, medical tables. London, HMSO.

${ }^{2}$ Howe, G M, National Atlas of Mortality in the United Kingdom. London, Nelson, 1963.

3 West, R R, and Lowe, C R, International fournal of Epidemiology, 1976, $\mathbf{5}, 195$

${ }^{4}$ Ashford, J R, Read, K L Q, and Riley, V A, International fournal of Epidemiology, 1973, 2, 31.

5 Annual Reports of Registrar General of Births, Deaths, and Marriages in England, 1837-80. London, HMSO, 1838-82.

${ }^{6}$ Logan, R F L, et al, Dynamics of Medical Care. London, London School of Hygiene and Tropical Medicine, 1972.

7 Griffiths, D A T, Hospital, 1971, 67, 229.

${ }^{8}$ Ministry of Health, A Hospital Plan for England and Wales, Cmnd 1604. London, HMSO, 1962.

${ }^{9}$ Buxton, M J, and Klein, R E, British Medical fournal, 1975, 1, 345.

${ }^{10}$ Department of Health and Social Security, Health and Personal Social Service Statistics for England and Wales. London, HMSO (Annual).

11 Titmus, R M, Essays on the Welfare State. London, Allen and Unwin 1958.

12 Hart, J T, Lancet, 1971, 1, 405.

${ }^{13}$ McKeown, T, and Lowe, C R, An Introduction to Social Medicine. London, Blackwell, 1974.

${ }^{14}$ Martini, C J M, et al, Health Indices Sensitive to Medical Care Variation. Nottingham, University of Nottingham, 1975.

\title{
Genetic susceptibility in diabetes mellitus: analysis of the HLA association
}

\author{
A G CUDWORTH, J C WOODROW
}

British Medical fournal, 1976, 2, 846-848

\section{Summary}

Two hundred and eighty-eight patients with insulindependent diabetes who were aged 30 or under at onset and 150 patients with late-onset diabetes, 50 of them dependent on insulin and 100 not dependent on insulin, were HLA-typed. There was a significant positive association between the young-onset insulin-dependent patients and HLA-B8, BW15, and B18 and a significant negative association with $B 7$. These data were combined with those from two other centres. There was a significant concordance for the distribution of all the HLA antigens among these three series, producing evidence in favour of an HLA-linked diabetogenic gene (or genes) having a major role in all cases of juvenile-onset insulin-dependent diabetes.

There was a positive association between late-onset insulin-dependent diabetes and $B 8$, but no association between non-insulin-dependent diabetes and the HLA system. This provides further evidence for the existence of different pathogenetic mechanisms in the two major clinical forms of diabetes mellitus.

\section{Introduction}

There is a positive association between juvenile-onset diabetes and HLA-B8 and BW15 in both Copenhagen and Liverpool. ${ }^{1-3}$

Department of Medicine, University of Liverpool, Liverpool L69 3BX A G CUDWORTH, MD, MRCP, senior lecturer in medicine J C WOODROW, MD, FRCP, reader in medicine

An increased prevalence of HLA-B18 in similar patients living in Montpellier has also been reported. ${ }^{4}$ One interpretation of these findings is that only those diabetics who are positive for $\mathrm{B} 8, \mathrm{BW} 15$, or B18 possess an HLA-linked diabetogenic gene. An alternative hypothesis is that the same HLA-linked disease susceptibility gene is present in all patients with juvenile onset diabetes but that because of linkage disequilibrium with the HLA-B locus, it occurs more often on chromosomes with certain B series genes-for example, B8 and BW15-than on others. Consideration must also be given to the possibility of several HLA-linked diabetogenic genes, associated in each case with particular alleles, interacting with different environmental factors.

We analysed the results of HLA typing in an enlarged series of patients with juvenile-onset diabetes, both on their own and together with the results from other centres. ${ }^{4}{ }^{5}$ HLA typing was also performed on patients with a later age of onset, both insulin and non-insulin dependent, to determine whether the basic genetic mechanisms underlying the aetiology of the disease were fundamentally different in the two major forms of clinical diabetes.

\section{Patients and methods}

Two hundred and eighty-eight patients with insulin-dependent diabetes with an age of onset of 30 years or less were HLA typed. Another 50 patients with insulin-dependent late onset diabetes and 100 with late-onset disease but no dependence on insulin were also typed. The 375 controls consisted mainly of normal blood donors living in the same geographical area. All the patients studied were Caucasian and permanently resident in the Liverpool area.

HLA typing was performed by the two-stage microlymphocytotoxicity method. ${ }^{6}$ Twenty-three specificities were determined using sera obtained from the National Tissue Typing Reference Laboratory, Bristol, and the serum bank of the National Institutes of Health, Bethesda, Maryland. 
Statistical methods-Relative risks and combined analysis of data were computed by the Woolf ${ }^{7}$ method as modified by Haldane. ${ }^{8}$ The probabilities estimated for comparing patients and controls were $2 \times \mathrm{P}, \mathrm{P}$ being derived from the normal probability integral of the corresponding $\chi^{2}$ values, this giving estimates close to those of the Fisher-Irwin exact test.

\section{Results}

The HLA-antigen frequencies for the Liverpool series with juvenile-onset diabetes are shown in table $I$. Previous findings of an increased frequency of HLA-B8 and BW15 were confirmed. For B8, $\mathbf{P}=2.8 \times 10^{-7}$ after multiplying by 23 , the number of specificities tested. When this correction was applied to the $B W 15$ data $P=0.069$. There was also an increase in the frequency of B18 $(P=0.09)$ after applying the above correction. The relative risks for $\mathrm{B} 8, \mathrm{BW} 15$, and B18 were $2 \cdot 54,2 \cdot 0$, and $2 \cdot 4$ respectively.

TABLE II-Age of onset in relation to different $H L A$ phenotypes. Patients who were positive for combinations of $B 8, B W 15$, and $B 18$ were included

\begin{tabular}{|c|c|c|c|c|c|c|}
\hline \multirow{2}{*}{ HLA } & \multicolumn{6}{|c|}{ Age of onset (years) } \\
\hline & $0-5$ & $6-10$ & $11-15$ & $16-20$ & $21-25$ & $26-30$ \\
\hline $\begin{array}{l}\text { B8 } \\
\text { BW15.. } \\
\text { B18 } \\
\text { Other }\end{array}$ & $\begin{array}{r}10 \\
4 \\
6 \\
14\end{array}$ & $\begin{array}{r}32 \\
10 \\
7 \\
14\end{array}$ & $\begin{array}{r}64 \\
19 \\
7 \\
27\end{array}$ & $\begin{array}{r}20 \\
7 \\
7 \\
10\end{array}$ & $\begin{array}{r}9 \\
7 \\
3 \\
14\end{array}$ & $\begin{array}{r}13 \\
5 \\
3 \\
7\end{array}$ \\
\hline
\end{tabular}

$\chi^{2}=19 \cdot 87 ; \mathrm{DF}=15 ; \mathrm{P}>0 \cdot 1$

On the other hand, the relative risks for $\mathrm{B} 5, \mathrm{~B} 7$, and $\mathrm{BW} 35$ were particularly low- $0.44,0.43$, and 0.57 respectively-although only the data for $B 7$ showed this to be significant $\left(P=5.5 \times 10^{-4}\right.$ after correction for the number of specificities tested). The total $\chi^{2}$ value for the $\mathrm{B}$ series comparisons was 93.22; $\mathrm{DF}=13 ; \mathrm{P}=3.4 \times 10^{-14}$.

To throw light on the possible genetic mechanisms, certain combinations of $B$ series antigens were examined (table $A^{*}$ ). Twenty-one $(7 \cdot 3 \%)$ diabetics had both HLA-B8 and BW15 compared with five $(1.33 \%)$ controls, giving a relative risk of 5.4 . This relative risk seemed to be the additive risk for $\mathrm{B} 8$ and $\mathrm{BW} 15$ independently. The numbers in relation to $\mathrm{B} 8, \mathrm{~B} 18$, and $\mathrm{BW} 15, \mathrm{~B} 18$ were too small to draw conclusions. Thirty-seven $(12.9 \%)$ patients typed B8 blank-that is, possible homozygous B8-compared with $27(7 \cdot 2 \%)$ controls. By HLA typing the parents homozygosity for B8 was established in seven out of 11 patients typing as B8 blank. If this proportion was accurate for the 37 patients this would imply that of the 148 B8positive patients, 24 were homozygous $\mathrm{B} 8$ and 124 heterozygousa ratio of 1:5. This ratio in the control population is known to be

*Copies of tables A, B, and C may be obtained from the authors.
$1: 11$, and there is a suggestion, therefore, that there are more B8 homozygotes among patients with juvenile-onset diabetes.

For the A series antigens, the sum of $\chi^{2}$ was $35.64 ; \mathrm{DF}=10$ $\mathrm{P}=10^{-4}$, suggesting a possible disturbance in the relation frequencies of $A$ series antigens. There was a low $P$ value in relation to $A 1$ and A11. An important consideration is the linkage disequilibrium that exists between certain A and B series antigens-for example, Al and B8. An increase, therefore, of B8 would be expected to be accompanied by an increase in A1. The frequency of Al in known heterozygous B8 diabetics was compared with that in controls. If there is an independent increase in the frequency of $\mathrm{Al}$ it should have appeared in this comparison. There were 111 HLA-B8 diabetic heterozygotes, 88 of whom were A1 positive, while of 106 similar controls 75 were A1 positive $\left(\chi^{2}=2.09 ; P=0.15\right)$. There was thus no evidence of an increase in the frequency of Al independently of that in B8. The reduction in the frequency of $A 11$ was significant $(P=0.02$, after taking into consideration the number of specificities).

Combined analysis (table B)-The data from this study were combined with the results from two other centres. ${ }^{4}{ }^{5}$ The increase in frequency of $\mathrm{B} 8\left(\mathrm{P}=3.7 \times 10^{-12}\right)$ was confirmed, and the increase in the frequencies of $\mathrm{BW} 15$ and $\mathrm{B} 18$ became highly significant $\left(\mathbf{P}=3.3 \times 10^{-6}\right.$ and $3.3 \times 10^{-4}$ respectively). It was noteworthy that the decrease in the frequency of $B 7$ was strongly confirmed $(P=2.8 \times$ $\left.10^{-7}\right)$, and there were low $\mathrm{P}$ values for $\mathrm{B} 5, \mathrm{~B} 12$, and $\mathrm{B} 35$, which all had a reduced relative risk $(0.58,0.66$, and 0.64 respectively). The series agreed in showing a low relative risk $(0.44)$ for $\mathrm{A} 11\left(\mathrm{P}=3.5 \times 10^{-4}\right)$.

Concordance between three centres-The observation that there were disturbances in the frequencies of several antigens raised the possibility that there may have been a regular pattern recurring in studies carried out in different centres. To test this hypothesis, the logarithms of the relative risks for all the antigens were ranked in order of increasing value. The Kendall rank correlation analysis was then carried out to test for concordance between the three series. For the $B$ series the concordance value was $0.64(P<0.01)$ and for the $A$ series $0.79(P<0.01)$.

Late-onset insulin-dependent diabetes (table $\mathrm{C}$ )-The prevalence of HLA-B8 among the 50 patients with an age of onset of greater than 30 years (31-70 years, mean 47.4 years), all of whom were insulin dependent from the beginning of their disease, was significantly increased $\left(\chi^{2}=4.95 ; P=0.03\right.$; relative risk $\left.=2.05\right)$. There were also suggestive but insignificant increases in BW15 and B18 (relative risks 1.74 and 1.63 respectively).

Late-onset non-insulin-dependent diabetes (table C)-The frequency distribution of HLA antigens in 100 patients with late-onset diabetes (33-82 years, mean 57.6 years) who were not dependent on insulin showed no departure from the expected frequencies for any antigen. For the $B$ series the total $\chi^{2}$ value was $5.57 ; \mathrm{DF}=12 ; \mathrm{P}=0.94$

Age of onset and HLA phenotypes-The relation between age of onset in the Liverpool patients with juvenile-onset diabetes and HLA phenotypes is shown in table II. The peak age of onset was 11-15 years, and analysis showed that there was no significant evidence of heterogeneity for age of onset and particular HLA phenotypes.

TABLE I-HLA antigen frequencies in insulin-dependent diabetics who were aged 30 or under at onset (Liverpool data)

\begin{tabular}{|c|c|c|c|c|c|c|c|c|}
\hline \multirow{2}{*}{ HLA } & \multicolumn{2}{|c|}{ No of patients } & \multicolumn{2}{|c|}{ No of controls } & \multirow{2}{*}{$\begin{array}{l}\text { Relative risk } \\
\text { (Haldane) }\end{array}$} & \multicolumn{2}{|c|}{$x^{2}$} & \multirow{2}{*}{$\underset{\text { value }}{\mathbf{P}}$} \\
\hline & Positive & Negative & Positive & Neagtive & & (Ordinary) & (Yates) & \\
\hline \multicolumn{9}{|c|}{$A$ series } \\
\hline $\begin{array}{l}\text { A1 } \\
\text { A2 } \\
\text { A3 } \\
\text { A9 } \\
\text { A10 } \\
\text { A11 } \\
\text { A28 } \\
\text { A29 } \\
\text { AW30/31 } \\
\text { AW32 }\end{array}$ & $\begin{array}{r}133 \\
146 \\
66 \\
64 \\
14 \\
13 \\
15 \\
21 \\
7 \\
5\end{array}$ & $\begin{array}{l}155 \\
142 \\
222 \\
224 \\
274 \\
275 \\
273 \\
192 \\
147 \\
163\end{array}$ & $\begin{array}{r}128 \\
170 \\
110 \\
73 \\
32 \\
46 \\
18 \\
27 \\
18 \\
23\end{array}$ & $\begin{array}{l}247 \\
205 \\
265 \\
302 \\
343 \\
329 \\
303 \\
306 \\
302 \\
305\end{array}$ & $\begin{array}{l}1.65 \\
1.24 \\
0.72 \\
1.18 \\
0.56 \\
0.35 \\
0.93 \\
1.24 \\
0.83 \\
0.44\end{array}$ & $\begin{array}{r}9.90 \\
1.88 \\
3.44 \\
0.75 \\
3.40 \\
12.08 \\
0.05 \\
0.50 \\
0.24 \\
3.40\end{array}$ & $\begin{array}{r}9 \cdot 41 \\
1 \cdot 67 \\
3 \cdot 12 \\
0 \cdot 60 \\
2 \cdot 86 \\
11 \cdot 14 \\
0.00 \\
0 \cdot 30 \\
0 \cdot 07 \\
2.68\end{array}$ & $\begin{array}{l}0.002 \\
0 \cdot 197 \\
0.077 \\
0.440 \\
0.091 \\
0.001 \\
0.970 \\
0.582 \\
0.785 \\
0.101\end{array}$ \\
\hline \multicolumn{9}{|c|}{$B$ series } \\
\hline $\begin{array}{l}\text { B5 } \\
\text { B7 } \\
\text { B8 } \\
\text { B12 } \\
\text { B13 } \\
\text { B14 } \\
\text { B18 } \\
\text { B27 } \\
\text { BW 15 } \\
\text { BW17 } \\
\text { BW22 } \\
\text { BW35 } \\
\text { BW40 }\end{array}$ & $\begin{array}{r}13 \\
44 \\
148 \\
68 \\
10 \\
16 \\
33 \\
14 \\
52 \\
12 \\
10 \\
19 \\
43\end{array}$ & $\begin{array}{l}275 \\
244 \\
140 \\
220 \\
278 \\
272 \\
255 \\
274 \\
236 \\
276 \\
278 \\
249 \\
245\end{array}$ & $\begin{array}{r}37 \\
111 \\
110 \\
106 \\
20 \\
28 \\
19 \\
29 \\
37 \\
27 \\
19 \\
45 \\
43\end{array}$ & $\begin{array}{l}338 \\
264 \\
265 \\
269 \\
355 \\
347 \\
356 \\
346 \\
338 \\
348 \\
356 \\
330 \\
332\end{array}$ & $\begin{array}{l}0.44 \\
0.43 \\
2.54 \\
0.79 \\
0.65 \\
0.74 \\
2.40 \\
0.62 \\
2.00 \\
0.57 \\
0.69 \\
0.57 \\
1.35\end{array}$ & $\begin{array}{r}6 \cdot 69 \\
18 \cdot 65 \\
33.33 \\
1 \cdot 82 \\
1 \cdot 31 \\
0.96 \\
9 \cdot 21 \\
2 \cdot 22 \\
9 \cdot 40 \\
2 \cdot 71 \\
0.99 \\
4 \cdot 20 \\
1 \cdot 73\end{array}$ & $\begin{array}{r}5.95 \\
17.86 \\
32.41 \\
1.59 \\
0.91 \\
0.68 \\
8.34 \\
1.77 \\
8.71 \\
2.19 \\
0.65 \\
3.67 \\
1.44\end{array}$ & $\begin{array}{c}0.015 \\
2.4 \times 10^{-5} \\
1.2 \times 10^{-8} \\
0.207 \\
0.340 \\
0.411 \\
0.004 \\
0.184 \\
0.003 \\
0.139 \\
0.422 \\
0.055 \\
0.230\end{array}$ \\
\hline
\end{tabular}




\section{Discussion}

Diabetes is a clinically heterogeneous disorder. The two major forms of the disease are characterised by differences in abruptness of onset, tendency to ketosis, and dependence on insulin. Our findings provide further support for the concept that these are probably two separate diseases with different underlying pathogenic mechanisms.

In juvenile-onset diabetes or insulin-dependent diabetes irrespective of age of onset there is good evidence that one or more HLA-linked genes are important in producing susceptibility. The association with HLA-B8 and BW 15 is confirmed and in our enlarged study we found new evidence for an association with B18. Thus, the relative risk of developing this type of diabetes is increased two- or three-fold in those people who are positive for HLA-B8, BW15, or B18. The increases in the frequencies of $\mathrm{B} 8$ and $\mathrm{BW} 15$ were smaller in the Montpellier series, but there was no significant heterogeneity in this respect with the other two centres.

Possibly these findings indicate the presence of one or more diabetogenic genes in the HLA chromosomal region that tend to occur particularly on chromosomes with $\mathrm{B} 8, \mathrm{BW} 15$, and $\mathrm{B} 18$. In our analysis, however, in addition to the increases in frequencies of these antigens, the expected overall decrease in the frequencies of the other $B$ series antigens did not seem to be randomly distributed but affected some antigens in particularfor example, $\mathrm{B} 7$ (relative risk $0.44 ; \mathrm{P}=2.8 \times 10^{-7}$ ). In this respect there was a significant concordance between the three series. This would not be expected if the diabetogenic gene (or genes) was present only on $\mathrm{B} 8, \mathrm{BW} 15$, or $\mathrm{B} 18$ chromosomes.

Does the evidence point to the presence of a single major HLA-linked diabetogenic gene or multiple genes possibly in disequilibrium with different HLA alleles? We once suggested that there may be heterogeneity for HLA-B8 and BW15 in relation to age of onset, ${ }^{9}$ indicating the possibility that different environmental agents-for example, viruses-were important at different ages, their action depending on the presence of different HLA-linked diabetogenic genes. Our present findings do not support this hypothesis. Evidence in favour of there being more than one HLA-linked gene, possibly operating by different pathogenetic mechanisms in juvenile-onset diabetes, ${ }^{10}$ is provided by the finding that the relative risk appears to be additive when both $\mathrm{B} 8$ and $\mathrm{BW} 15$ are present. There is suggestive evidence in the Liverpool data that the relative risk is higher for those who are homozygous for B8 than for those who are heterozygous B8 but not as high as that for B8, BW 15 individuals. This supports the hypothesis that the risk of developing this type of diabetes is not additive when the gene operating via one particular mechanism is inherited on both HLA chromosomes, in contrast with what happens when a person inherits two different diabetogenic genes. None of these differences are significant, however, and it remains an open question whether these particular combinations of HLA antigens are associated with different relative risks. An accurate estimation of relative risk for established homozygous B8 and BW15 individuals in relation to the corresponding heterozygotes and B8, BW 15 heterozygotes would be useful in clarifying this issue. A futher method of seeking heterogeneity in respect of diabetogenic genes was provided by the study of identical twins, but the results were again inconclusive. ${ }^{11}$

A reasonable interpreiation of the present evidence is that there is one major HLA-linked diabetogenic gene, which, because of linkage disequilibrium with the $\mathrm{B}$ locus, is nonrandomly distributed in relation to the whole series of $\mathrm{B}$ locus antigens. This is supported by the study of the pattern of inheritance of HLA haplotypes by diabetic siblings. ${ }^{9}$ None of the evidence available at present refutes this concept, which provides a useful working hypothesis for further studies.

In the limited study of 50 insulin-dependent diabetics with an age of onset greater than 30 years there was evidence of a significant association with HLA-B8, and the general pattern of frequency distribution for the $\mathrm{B}$ series antigens was similar to that in the series with juvenile-onset diabetes. This suggests that in these patients with late-onset insulin-dependent diabetes the same pathogenetic mechanisms that produce the disease seen predominantly in the young are operating. There was no evidence to suggest a significant departure from the normal frequency of any of the HLA antigens in 100 patients with lateonset diabetes who were not dependent on insulin. This provides strong evidence for the existence of genetic heterogeneity in diabetes.

The mode of action of the HLA-linked diabetogenic gene in insulin-dependent diabetes is still speculative. Recently, islet cell antibodies have been found in $24^{\circ}$ o of a random series of patients with juvenile-onset diabetes. ${ }^{12}$ In an extended study the prevalence of these antibodies in non-insulin-dependent diabetics was low $\left(2 \cdot 7^{\circ}{ }_{0}\right)$, but in insulin-dependent diabetics with a late onset of symptoms the prevalence was similar to that found in insulin-dependent patients with an early onset of disease $\left(21 \cdot 1^{\circ}{ }^{\circ}\right)$. No association was found between the presence of islet cell antibodies and any particular phenotype. A possible unifying hypothesis is that in insulin-dependent diabetes, irrespective of age of onset, there is an HLA-linked gene that permits interaction of a virus with specific cell membrane antigens, resulting in direct viral invasion and destruction of the $\beta$-cells. Alternatively, this interaction between the virus and membrane receptor may result in neoantigen formation, resulting in antibody-mediated $\beta$-cell destruction.

We are indebted to the National Tissue Typing Reference Laboratory, Bristol, and the serum bank of the National Institutes of Health, Bethesda, Maryland, for supplying typing antisera. This work was supported in part by the Mersey Regional Health Authority Medical Research Committee. Mr N Usher, Mrs J Usher, Mrs A Dodd, and Miss V Moss gave valuable technical help.

Copies of the unpublished tables may be obtained from Dr A G Cudworth, Department of Medicine, University of Liverpool, Ashton Street, PO Box 147, Liverpool L69 3BX.

\section{References}

1 Nerup, J, et al, Lancet, 1974, 2, 864.

2 Cudworth, A G, and Woodrow, J C, Lancet, 1974, 2, 1153.

3 Cudworth, A G, and Woodrow, J C, Diabetes, 1975, 24, 345.

- Seignalet, J, et al, Tissue Antigens, 1975, 6, 272.

5 Sveigaard, A, personal communication based on original data from Nerup et al. ${ }^{1}$

6 Terasaki, P I, and McClelland, J D, Nature, 1964, 204, 998.

7 Woolf, B, Annals of Human Genetics, 1955, 19, 251.

${ }^{8}$ Haldane, J B S, Annals of Human Genetics, 1955, 20, 309.

9 Cudworth, A G, and Woodrow, J C, British Medical fournal, 1975, 3, 133.

10 Svejgaard, A, et al, Transplantation Reviews, 1975, 22, 1.

11 Nelson, P G, et al, Lancet, 1975, 2, 193.

1.2 Lendrum, R, et al, British Medical fournal, 1976, 1, 1565. 